Cell Research (2002); 12(3-4):223-228

http://www.cell-research.com

\title{
Transplanted neuronal precursors migrate and differentiate in the developing mouse brain
}

\author{
Wei Min Peng , Li Li YU, Chun Ying BAO, Fan LiAO, Xue Sheng LI, Ming Xue ZUO* \\ Biomedical Research Institute, Beijing Normal University, Beijing 100875, China
}

\begin{abstract}
The subventricular zone (SVZ), lining the lateral ventricle in forebrain, retains a population of neuronal precursors with the ability of proliferation in adult mammals. To test the potential of neuronal precursors in adult mice, we transplanted adult SVZ cells labeled with fluorescent dye PKH26 into the lateral ventricle of the mouse brain in different development stages. The preliminary results indicated that the grafted cells were able to survive and migrate into multiple regions of the recipient brain, including SVZ, the third ventricle, thalamus, superior colliculus, inferior colliculus, cerebellum and olfactory bulb etc; and the amount of survival cells in different brain regions was correlated with the development stage of the recipient brain. Immunohistochemical studies showed that most of the grafted cells migrating into the specific target could express neuronal or astrocytic marker. Our results revealed that the neuronal precursors in adult SVZ still retained immortality and ability of proliferation, which is likely to be induced by some environmental factors.
\end{abstract}

Key words: subventricular zone (SVZ), neuronal precursor, cell transplantation, migration, differentiation, mouse.

\section{INTRODUCTION}

It was usually regarded that the neurogenesis has terminated in the central nervous system of the adult mammals. However, the recent researches found that some neuronal stem cells maintained activity in adult, especially in the dentate gyrus of hippocampus and the subventricular zone (SVZ)[1],[2], and the neuronal precursors derived from these stem cells could migrate into the olfactory bulb through the rostral migration stream (RMS) and differentiate into local interneurons[3],[4]. With their potential to produce neurons, now SVZ cells have been widely used to study the mechanism of neuronal migration and brain repair in adult mammalian brain [5],[6]. It has been known that the portion of SVZ is the larg-

* Corresponding author, E-mail: mxzuo@bnu.edu.cn Tel: 01062208558

Received Dec-21-2002 Revised April-22-2002 Accepted May-62002 est pool of neuronal precursors in many adult vertebrates[7],[8]. Usually, the neuronal precursor cells derived from the neuronal stem cells lay in or adjacent to the ventricular zone (VZ), and migrate outside SVZ[9]. Therefore, it was considered that the wall of the brain ventricles played an important role in the diffusion and activation of the transplanted cells[10]. Obviously, the transplant study of the adult SVZ cells will, not only understand the mechanism of migration and survival of the neuronal precursor cells in adult, but also provide a base for improving strategies of neuronal replacement.

It has been reported that the SVZ precursors from the adult mice could differentiate into neurons or glia in vitro[11]. Also, the neuronal precursors from neonatal mouse SVZ have been showed to be able to migrate and differentiate into neurons in the multiple regions of the embryonic brain, mainly in the olfactory bulb(OB), septum, thalamus, hypothalamus 
Transplanted neuronal precursors migrate and differentiate in the developing mouse brain

and cerebellum[12]. More recently, Snyder et al[13] reported that the transplanted stem cells from the human embryo could differentiate into neurons in the forebrain of the embryonic primate. These findings raised a question whether transplanted precursors from adult brain were able to survive and differentiate into mature neurons in the developing recipient brain. Transplants of adult SVZ cells have not been revealed to migrate into and differentiate within non-OB central nervous system, even though the local migration and incorporation occur with neonatal SVZ cells grafted into neonatal striatum [12]. Furthermore, it is of interest whether the adult SVZ precursors have the same plasticity or potential as the embryonic precursors. To test this hypothesis, we injected the dissociated SVZ cells from the adult into the lateral ventricles of the mouse brain at the different development time. Here was showed that the grafts from the adult SVZ cells were able to incorporate into the developing brain and differentiate into neurons. It is hoped that the present results will contribute to the research for the potential of adult SVZ precursors in the treatment strategies of the brain trauma and neural dysfunction.

\section{MATERIALS AND METHODS}

\section{Preparation of SVZ donor cells}

Fifty-seven pregnant Kun Ming(KM)mice were used for these experiments (supplied by the Experimental Animal Center of the Medical Department of Peking University).

The 3-5 months old male mice $(\mathrm{n}=38)$ were anesthetized with $0.3 \%$ sodium pentobarbital ( $40 \mathrm{mg} / \mathrm{Kg}$ body weight) and perfused through the ascending aorta with the sterilized D-Hanks. The SVZ explants were dissected from a coronal slice $(1 \sim 2 \mathrm{~mm}$ thick $)$ extending between the anterior commissure and the third ventricle. A strip of tissue (about $0.1 \mathrm{~mm}$ wide; $2 \sim 4 \mathrm{~mm}$ long) was extracted along the lining of the lateral ventricle under the corpus callosum and cut with scalpels into pieces. After digested with 0.06 $\mathrm{mg} / \mathrm{ml}$ papain at $37^{\circ} \mathrm{C}$ for $30 \mathrm{~min}$, the donor tissues were rinsed with 1640 medium and then dispersed into single cell suspension. The donor cells were labeled with PKH26 (Sigma) in the Diluent C store solution (1:100) for 10min at room temperature and treated with the equal volume of serum about $1 \mathrm{~min}$ to block the PKH26 reaction. After washed three times in 1640 medium, the donor cells were centrifuged and resuspended in 1640 medium at 50, $000 \mathrm{cells} / \mu \mathrm{l}$. Before transplant, Trypan blue $(0.1 \%)$ was sometimes added into the donor cell suspension to check the injection position in the recipient embryos.

The grafted SVZ cell types were determined with NeuN (neuron-specific nuclear protein, Sigma) and GFAP (glial fibrillary acidic protein, Jackson Corporation) immunostaining by using smear method, and double stained with $0.1 \%$ Evans blue. Three microscopic fields on the same smear slide were selected randomly for cell type count and statistic analysis.

\section{Recipient mice and group}

The donor cells were injected into the lateral ventricle of embryos in the pregnant KM mice $(n=57)$. The date of transplant operation was planned on E15, E17 and P0 (E0: vaginal date, P0: date of birth), separately. The recipient subjects were sacrificed on P3, P20, P30 and P90, separately. Ten experimental groups were divided by the date of transplant (left by slant) and the date of sacrifice (right by slant), indicated as E15/P3, E17/P3, P0/P3 and etc.

\section{Transplant operation}

The timed-pregnant KM mice were anesthetized with sodium pentobarbital and injected $120-250 \mu \mathrm{l} 2.5 \% \mathrm{MgSO}_{4}$ to relax the smooth muscle. An incision was made along the abdominal midline to expose the uterine horns on the warm pad $\left(37^{\circ} \mathrm{C}\right)$. Every embryo was kept upward to show the forebrain ventricles and injected about $1 \mu \mathrm{l}$ donor cells suspension into the lateral ventricles, one by one. In P0 group, the cell suspension was injected directly into the lateral ventricle.

\section{Immunohistochemistry}

The anesthetized recipient mice were perfused with $0.9 \%$ saline followed by $4 \%$ polyformaldehyde in PBS. The brains were removed and stored in $4 \%$ polyformaldehyde at $4^{\circ} \mathrm{C}$ for additional 4 $\mathrm{h}$, and then transferred to $20 \%$ sucrose for $24 \mathrm{~h}$. The sagittal brain sections were cut at $16 \mathrm{~mm}$ with microtome and every eighth sections were collected. For the GFAP immunostaining, the sections were treated with $3 \%$ normal goat serum for $1-3 \mathrm{~h}$ at $4^{\circ} \mathrm{C}$ to block the non-specific staining and then incubated in the rabbit anti-GFAP antibody 1:500 in PBS overnight at $4^{\circ} \mathrm{C}$. After rinsing three times in PBS, sections were incubated in the goat antirabbit IgG-FITC (Jackson Corporation) 1: 100 for $2 \mathrm{~h}$ at room temperature. For NeuN immunostaining, the sections were treated with normal goat serum same as for GFAP staining and incubated in the mouse anti-NeuN monoclonal antibody 1:500 in PBS at $4^{\circ} \mathrm{C}$ for $48 \mathrm{~h}$, and rinsed and incubated in the goat anti-mouse IgG-FITC (Jackson Corporation) 1:85 for $2 \mathrm{~h}$ at room temperature. The negative control sections were incubated in the same diluted solution without the primary antibody but the other procedures were same as above.

\section{Observation and statistics}

PKH26 presents the red fluorescence $(\mathrm{Max}=567 \mathrm{~nm})$ excited by green rays $(\mathrm{Max}=551 \mathrm{~nm})$. DNA fluorescent dye, Hoechst 33342, was used to label background cells to confirm the PKH26 labeled cells. Hoechst 33342 presents blue fluorescence excited by ultraviolet rays. The double-labeled cells with PKH26 and NeuN or GFAP were also observed and counted, separately. Images were acquired by SPOT-II and statistics analysis were performed with SPSS8.0 (ANOVA and LSD). 


\section{RESULTS}

The phenotypes of the donor cells from adult SVZ

The donor cells on smear slides were immunostained by NeuN and GFAP. The results showed that NeuN-positive cells accounted for $3.1 \%$ $(\mathrm{X}=9.46 / 305.3, \mathrm{n}=6)$, GFAP-positive cells accounted for $2.5 \%(X=10.3 / 411.67, n=6)$, and the rest represent NeuN and GFAP-negative cells.

The grafted SVZ cells incorporate into multiple regions in the developing mouse brain

To reveal the morphology of the living cells, the grafted SVZ cells were labeled with fluorescent lipophilic dye PKH26 before transplantation. PKH26labeled cells were detected in multiple regions of the recipient brain (Tab 1 ). With different surviving times, the PKH26-labeled cells were remarkably detected in the SVZ of embryonic or neonatal brains in all groups. The main regions where graft-derived cells existed were the third ventricle, thalamus, superior colliculus, inferior colliculus, cerebellum, pons and the retro-cortex etc.. Only a few PKH26 labeled cells were detected in the internal capsule and the area behind hippocampus. Only in E17/P30, there were a large quantity of labeled cells in olfactory bulb (Fig 1, Fig 2).

Tab 1. Distribution of PKH26-positive cells in the recipient brain

\begin{tabular}{|c|c|c|c|c|c|c|c|c|c|c|}
\hline \multirow[b]{2}{*}{ Regions } & \multicolumn{3}{|c|}{$\mathrm{E} 15(\mathrm{n}=14)$} & \multicolumn{3}{|c|}{$\mathrm{E} 17(\mathrm{n}=10)$} & \multicolumn{3}{|c|}{$\mathrm{P} 0(\mathrm{n}=11)$} & \multirow[b]{2}{*}{$\begin{array}{r}\text { P30 } \\
(\mathrm{n}=4)\end{array}$} \\
\hline & $\begin{array}{r}\text { P3 } \\
(n=3)\end{array}$ & $\begin{array}{r}\mathrm{P} 20 \\
(\mathrm{n}=4)\end{array}$ & $\begin{array}{r}\text { P30 } \\
(\mathrm{n}=4)\end{array}$ & $\begin{array}{r}\text { P90 } \\
(\mathrm{n}=3)\end{array}$ & $\begin{array}{r}\text { P3 } \\
(n=3)\end{array}$ & $\begin{array}{r}\text { P20 } \\
(n=3)\end{array}$ & $\begin{array}{r}\text { P30 } \\
(\mathrm{n}=4)\end{array}$ & $\begin{array}{r}\text { P3 } \\
(\mathrm{n}=3)\end{array}$ & $\begin{array}{r}\mathrm{P} 20 \\
(\mathrm{n}=4)\end{array}$ & \\
\hline SVZ & 624.0 & 176.0 & 213.3 & 50.0 & 1536.0 & 1648.0 & 0 & 480.0 & 1360.0 & 288.0 \\
\hline $3 \mathrm{~V}$ & 362.7 & 202.7 & 85.3 & - & 3498.7 & 2032.0 & - & 53.3 & 96.0 & 341.3 \\
\hline RMS & 21.3 & - & - & - & - & - & 10.7 & - & 48.0 & - \\
\hline $\mathrm{OB}$ & & - & - & - & - & - & 13620.0 & - & - & - \\
\hline Thalamus & 208.0 & 5.3 & 170.7 & 38.0 & - & - & - & 4.7 & 234.7 & 10.7 \\
\hline $\mathrm{LH}$ & 74.6 & 942.7 & - & - & - & - & - & - & - & - \\
\hline $\mathrm{SC}$ & 9209.3 & 21.3 & 10.7 & - & - & 272.0 & - & - & - & - \\
\hline IC & 96.0 & 69.3 & - & 12.0 & - & 240.0 & - & - & 10.7 & - \\
\hline Cerebellum & 10.7 & 224.0 & 496.0 & 61.0 & - & 324.0 & 32.0 & 26.7 & 66.3 & - \\
\hline Pons & 1077.3 & 162.7 & 245.3 & - & - & 40.0 & - & 5.3 & 90.7 & 48.0 \\
\hline Retro-cortex & 160.0 & 426.7 & - & - & 218.7 & 136.0 & - & - & 117.3 & 618.7 \\
\hline Internal capsule & - & 80.0 & - & - & - & - & - & - & - & - \\
\hline $\mathrm{ABH}$ & - & - & - & - & - & - & - & 101.3 & 21.3 & 170.7 \\
\hline
\end{tabular}

3V: the third ventricle; OB: olfactory bulb; LH: lateral hypothalamic area; SC: superior colliculus; IC: inferior colliculus; ABH: area behind the hippocampus.

The differentiation of the grafted precursors in the developing mouse brain

The PKH26 stained sections were double-labeled with mouse anti-NeuN monoclonal antibody or rabbit anti-GFAP antibodies in the recipient brain sections. Most of the PKH26-labeld cells also showed another fluorescence. align = right This indicated that some grafted cells may had neuronal or astrocytic phenotypes in the recipient brains (Fig 3). In many cases, cell morphology was detected with $0.1 \%$ Evans blue, the lipophilic dye. The statistics analysis of the double-labeled cells in P30 and P90 showed that the NeuN-positve cells in SVZ, cerebellum and olfactory bulb represent $12.6 \%, 23.1 \%$ and $28.2 \%$, respectively. The GFAP-positive cells in SVZ, cerebellum and thalamus represent $21.66 \%, 20.12 \%$ and $18.74 \%$, respectively.

\section{DISCUSSION}

The previous studies demonstrated that the neuronal precursors derived from embryos could migrate into almost all regions of central nervous system in the embryonic brain in mice[12],[14],[15]. The grafted SVZ cells from neonatal mice also were able 

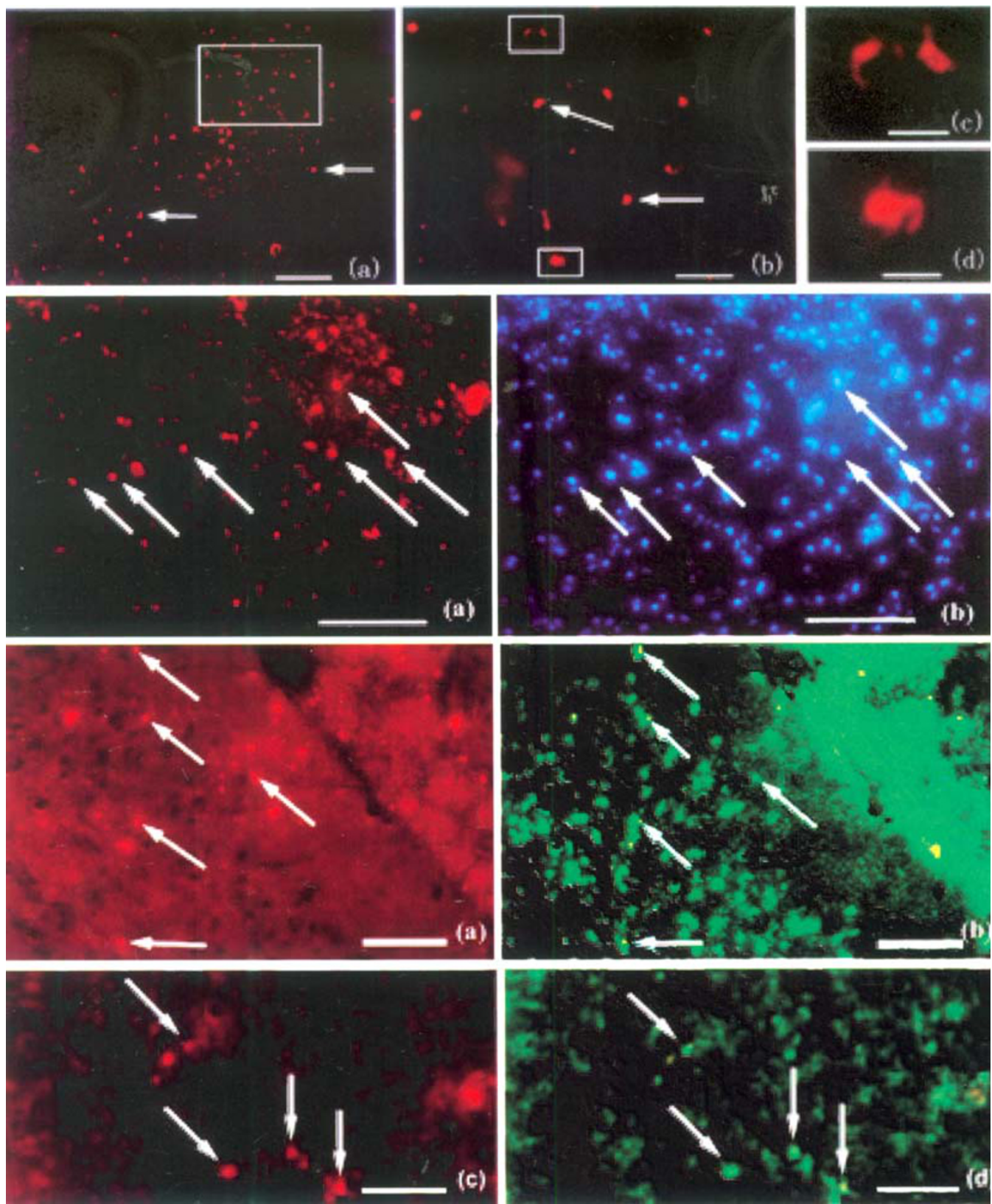

Fig 1.Observation of the PKH26-labeled cells transplanted in E17

The recipient was sacrificed in P30 and the brain was sectioned sagittally. PKH26-labeled cells show red fluorescence $(M a x=567 \mathrm{~nm})$ excited by green rays $(\mathrm{Max}=551 \mathrm{~nm})$. (a) is a photograph at low scale $(100 \times)$ to show the distribution of PKH26-labeled cells in the olfactory bulb; (b) is high-power photograph (400×) of the selected part in (a). (c) and (d) are further high-power photograph $(\mathrm{Bar}=50 \mu \mathrm{m})$ of selected part in (b), showing the morphology of PKH26-labeled cells.

\section{Fig 2.Observation of the PKH26-labeled cells coupled with Hoechst 33342 staining in E17/P30}

The PKH26-labeled cells (red) are showed in (a); Hoechst 33342-positive cells (blue) are showed in (b). Arrows in (a) and (b) show the same cells that are double-labeled for both PKH26 and Hoechst 33342. Left and right panels show the same sections. Bar $=100 \mu \mathrm{m}$

Fig 3.Double-labeled cells in the olfactory bulb (a, b) and SVZ (c, d)

Arrows in (a) and (b) show the same cells that are double-labeled with PKH26 (red) (a) and NeuN-positive cells (b) in E17/P30 groups. Arrows in (c) and (d) show the same cells that are double- labeled with PKH26(c) and GFAP (d) in $\mathrm{E} 15 / \mathrm{P} 90$ groups. $\mathrm{Bar}=100 \mu \mathrm{m}$ 
to survive in the embryonic brain but migrate more restrictedly than that from embryos, i.e. without migrating to the cortex and hippocampus[16]. Our transplanted studies revealed that the SVZ cells from the adult mice could survive in the developing brain (E15, E17 and P0) and migrate into multiple regions, but with the survival ability lower than the precursors from neonate[12]. The present result suggests that the donor neuronal precursors from adult have a similar activity in the developing recipient brain in the embryonic and neonatal mice; and that the potential of the neuronal precursors correlates with the recipient age, decreasing with aging.

In adult rodent, the SVZ precursors are proved to migrate into the $\mathrm{OB}$ along rostral migratory stream (RMS) in chain and then move to the different layers of OB in radial direction, but without migrating outside of OB[16]. Our studies showed that the SVZ cells from the adult migrated not only into OB but also into multiple regions out of $\mathrm{OB}$ in the developing brain in mice. It is possible that the migration of the donor cells was affected by some specific site factors in the recipient brain. In the present studies, the graft-derived SVZ cells migrating to OB were found only in E17/P30 (Fig 1, Fig 2), not in the other experimental groups. It is unlikely that this $\mathrm{OB}$ incorporation was caused by a misplaced injection into the parenchyma of RMS, as cells were injected bilaterally in lateral ventricular and were labeled in bilateral $\mathrm{OB}$ of the recipient brains. It is possible that the development of $\mathrm{OB}$ neurons originates in E17 and finishes in P30. In this critical period, either the expression of some factors may induce the migration to $\mathrm{OB}$, or the SVZ provides the optimum condition for the formation of $\mathrm{OB}$ precursor cells. However, This hypothesis requires further investigations.

In all experimental groups, PKH26-labeled cells were always found in SVZ of the recipient brains. This indicated that the SVZ is a starting point of the grafted cells to migrate outward, that this region is important for survival of the grafted cells. Our results show that there was different number of PKH26- labeled cells in the different regions of the recipient brain. It is possible that the plasticity differs in the different regions of the developing brain. From two reasonable explanations, one is that the grafted cells alter their direction or quantity of mi- gration after undergoing a specific selection, which is controlled by some specific factors before or after a critical development time. This specific selection has been reported in the songbird canary, which the migration of their neuronal precursor cells significantly depended on the spatial and temporal selection with the season variation[17]. The other is that some grafted cells, which have neither the definite direction to migrate nor the correct neuronal network to incorporate in, maybe occur the programmed cell death (apoptosis) at the different rate during migration and after entering different brain regions. It is maybe either absent of a proper local cue or presence of inhibitory signal[18]. Even though there has been not any direct evidence on apoptosis in the developing brain. Our results revealed that the quantity of the PKH26-labeled cells decreases in E15/ P90 compared to the other experimental groups.

Double-labeling by immunohistochemistry showed that some grafted cells differentiated into neurons or astrocytes after migrating into the target regions (Fig 3). Of the determination of the donor cell phenotypes ( $3.1 \%$ neurons and $2.5 \%$ glia), it was not established whether the double-labeled neurons or gila in the recipient brain came directly from the grafted neurons but not the grafted neuronal precursors. According to the statistics analysis of the quantity of the double-labeled cells in P30 and P90 groups, the percentage of neuron or glia in the recipient sections was higher (21.3\% and $20.2 \%$ ) than in the donor cell smeared slides. This result confirmed that some grafted neuronal precursors expressed neuronal phenotype after migrating into the special target. However, it is uncertain whether these grafted cells with neuronal phenotype establish synaptic connection with surrounding neurons, and whether they develope functions of a mature neuron.

The previous evidence showed that the SVZ cells migrated only into OB in the normal adult mice. Our transplant studies demonstrated that the SVZ cells from adult could migrate into multiple regions and differentiate into neurons in the developing brain in mice, and that the survival quantity of the donor SVZ cells correlated with the development time of the recipient brain. In the present researches, the grafted cells, including the nestin-positive cells from hippocampus transplanted into the cerebellum[18], the original cells from striatum transplanted into the 
developing cortex[19], the original cells expressing lacZ gene from mice cerebellum transplanted into hippocampus of neonatal rats or mice[20], were found to have the same phenotypes as the surrounding cells. All together these indicate that the local cues play an important role in migration and differentiation of the precursor cells in central nervous system. It would be interesting to investigate how the plasticity of the precursor cells is induced, and what factors control the plasticity of the precursor cells in adult. The answers to these questions will also help to develop the treatment of the degeneration and damage of central nervous system in adult.

\section{ACKNOWLEDGEMENTS}

We are grateful to Professor Zhijie Chang of Tsinghua University for help with the image analysis. This project was supported by National Science Funds (39870097) and Science Funds of Beijing (7992025).

\section{REFERENCES}

[1] Alvarez-buylla A. The origins of new neurons in the adult mammalian brain. Eur J Neurosci 2000; 28:713-26.

[2] Chiasson BJ, Tropepe V, Mosheas CM, Derkooy DV. Adult mammalian forebrain ependymal and subependymal cells demonstrate proliferation potential, but only subependymal cells have neural stem cell characteristics. J Neurosci 1999; 19:4462-71.

[3] Doetch F, Caille I, Lim D A, Garcia-Verdugo JM, AlvarezBuylla A. Subventricular zone astrocytes are neural stem cells in the adult mammalian brain. Cell 1999; 97:70316.

[4] Doetsch F, Garcia-Verdugo JM, Aovarez-Buylla A. Regeneration of a germinal layer in the adult mammalian brain. Proc Natl Acad Sci USA 1999; 99:1619-24.

[5] Cameron HA and McKay R. Stem cells and neurogenesis in the adult brain. Current Opinion Neurobiology 1998; 8:677-80.

[6] Chazal GV, Durbec P, Jankovski A, Rougon G, Cremer H. Consequences of neural cell adhesion molecule deficiency on cell migration in the rostral migratory stream of the mouse. J Neurosci 2000; 20:1446-57.

[7] Gould E, Cameron HA. Regulation of neuronal birth, migration and death in the rat dentategurus. Dev Neurosci 1996; 18:22-35.

[8] Ling CY, Zuo MX, Alvarez-buylla A, Cheng M-F. Neurogenesis in juvenile and adult ring doves. J Comp Neurol 1997; 379:300-12.

[9] Doetsch F, Garcia-Verdugo JM, Arvarez-Buylla A. Cellular composition and three- dimensional organization of the subventricular germinal zone in the adult mammalian brain. J Neuroscience 1997; 17:5046-61.

[10] Sarnat HB. Ependymal ractions to injury. A review. J Neuropathol Exp 1995; 54:1-15.

[11] Lois C, Alvarez-Buylla A. Proliferating subventricular zone cells in the adult mammalian forebrain can differentiate into neurons and glia. Proc Natl Acad Sci USA 1993; 90:2074-7.

[12] Lim DA, Fishell GJ, Alvarez-Buylla A. Postnatal mouse subventricular zone neuronal precursors can migrate and differentiate within multiple levels of the developing neuraxis. Proc Natl Acad Sci USA 1997; 94:14832-6.

[13] Ourednik V, Ourednik J, Flax JD, et al. Segregation of human stem cells in the developing primate forebrain. Science 2001; 293:1820-4.

[14] Lumelsky N, Blondel O, Laeng P, et al. Differentiation of embryonic stem cells to insulin-secreting structures similar to pancreatic islets. Science 2001; 292:1389-94.

[15] Gage F H. Mammalian neural stem cells. Science 2000; 287:1433-8.

[16] Lois C, Garcia-Verdugo JM, Alvarez-Buylla A. Chain migration of neuronal precursors. Science 1996; 71:97881.

[17] Conover JC, Doetsch F, Garcia-Verdugo JM, et al. Disruption of Eph/ephrin signaling affects migration and proliferation in the adult subventricular zone. Nat Neurosci 2000; 3:1091-7.

[18] Hsu Pi-en, Yu F, Feron F, Pickles JO, et al. Basic fibroblast growth factor and fibroblast growth factor receptors in adult olfactory epithelium. Brain Res 2001; 896: 188-97.

[19] Renfranz P, Cunningham M, McKay R D. Differentiation of the hippocampal stem cell line HiB5 upon implantation into the developing mammalian brain. Cell 1991; 66:713-29.

[20] Fishell G. Striatal precursors adopt cortical identities in response to local cues. Development 1995; 121:803-12.

[21] McKay R. Stem cells in the central nervous system. Science 1997; 276:66-77. 